\title{
Exploring the Direct and Indirect Effects of Emotional Leadership on Entrepreneurial Success of Start-ups in the Hospitality Sector (I)
}

\author{
ZHAO Jiahao \\ School of Business and Economics, Loughborough University, UK \\ Received: June 10, 2021 \\ Accepted: July 26, 2021 \\ Published: August 30, 2021
}

To cite this article: ZHAO Jiahao. (2021). Exploring the direct and indirect effects of emotional leadership on entrepreneurial success of start-ups in the hospitality sector (i). Asia-Pacific Journal of Humanities and Social Sciences, 01:2, 001-019, DOI: 10. 53789/j.1653-0465.2021.0102.001

To link to this article: https: //doi.org/10.53789/j.1653-0465.2021.0102.001

\begin{abstract}
Recently, there has been increasing interest in emotional leadership. Emotional leadership is primarily considered as an important element of contemporary leadership that is critical in achieving organisational objectives and goals. Such scholars as Bambale, Kassim and Musa explain emotional leadership as essential in leading followers through appropriate identification and management of emotions influencing the outcomes of the needs of these followers. Emotions have been found to follow certain logical patterns. It is established that proper use of emotions is imperative for successful leadership. Meanwhile, start-ups in the hospitality sector experience significant challenges in accessing human development resources. In particular, start-ups face immense difficulties in attracting highly skilled workers with extensive experience in the hospitality sector. It is appreciated that these challenges faced by start-ups in the hospitality sector can be mitigated with emotional leadership to a great extent. The general objective of this study is to explore the effects of emotional leadership on the entrepreneurial success of start-ups in the hospitality sector. The findings of this study will contribute to the body of knowledge on how emotional leadership influences the entrepreneurial success of start-ups.
\end{abstract}

Keywords: emotional leadership; entrepreneurship; hospitality sector; assertiveness; empathy; adaptability

Notes on the contributor: $\mathrm{ZHAO}$ Jiahao is a $\mathrm{PhD}$ candidate from School of Business and Economics, Loughborough University, the UK with an academic interest in socio-psychological perspectives of international human resource management, digital future, entrepreneurship, social cognitive theory and social policy.

\section{Introduction}

The main purpose of this chapter is to introduce the topic of the study. This study seeks to explore the direct and indirect effects of emotional leadership on the entrepreneurial success of start-ups that operate in the hospitality sector. In particular, this chapter will provide a brief background to the study and enumerate the main objectives of the study. It will also explain how this study seeks to achieve these objectives. Furthermore, this 
chapter will offer a justification for the research topic and a discussion on the importance, scope and limitation of the study. The main objective of this chapter is to enhance the understanding of the readers on the research topic and generate a clear perspective on why the research is conducted. Generally, this chapter provides the readers with a brief overview of the main objectives and aims of the proposed study. The following subsections will constitute this chapter: background of the study, research aims and objectives, problem statement, scope and limitations of the study, importance of the study and the structure of the study.

\subsection{Background of the study}

Leadership is identified as the process that involves motivation of people and mobilisation of resources that are needed in accomplishing common objectives and goals. It is widely acknowledged that leaders are important for organisational success since they direct the paths that facilitate individuals to work together and achieve common goals. The trait theory of leadership affirms that some leadership traits such as intelligence, openness, conscientiousness and self-efficacy are needed in the creation of effective leaders (Yusof 2014). Recently, there has been increasing interest in emotional leadership. Emotional leadership is largely considered as an essential element of contemporary leadership that is critical in the achievement of organisational objectives and goals. Bambale, Kassim and Musa (2016) explain emotional leadership as essentially in leading followers through appropriate identification and management of emotions influencing the outcomes of the needs of these followers. Emotions have been found to follow certain logical patterns (Stein and Book 2000). It is established that proper use of emotions is imperative for successful leadership. The leadership process, in general, is considered as a function of how leaders use their emotions.

The hospitality sector constitutes an important sector in any economy. In fact, the hospitality industry has become one of the major drivers of the European economy. The contribution of the hospitality industry has mainly been a generation of employment opportunities and has positive effects on the economy. In Europe alone, the hospitality industry generates over 16 million employment opportunities representing $7.8 \%$ of the aggregate employment. According to the International Labour Organization (ILO 2010), the hospitality sector continues to experience immense challenges that have constrained its growth in recent years. For instance, start-ups in the hospitality sector experience significant challenges in accessing human development resources. In particular, startups face immense difficulties in attracting highly skilled workers with extensive experience in the hospitality sector. The limited financial resources available to these start-ups in the hospitality sector have further exasperated the problem.

It is appreciated that these challenges faced by start-ups in the hospitality sector can be mitigated with emotional leadership to a great extent. Organisational leaders have several roles in the workplace. Essentially, leaders are the link between employees (followers) and the management of organisations. In addition, Bass (1998) explains that leaders provide strategic direction for their respective organisations. They also guide employees' behaviour towards the direction that offers great benefits for their organisations. To be effective in these roles, there is a general consensus that leaders must fully understand the policies and the main objectives and goals of their organisations. Such understanding is critical as it will facilitate these leaders in offering effective guidance to their followers towards the achievement of the overall objective of the organisation.

\subsection{Research problem}

Generally, a research problem identifies a troubling question in existing scholarly literature. The research 
problem points to and highlights the need for careful consideration and further interrogation on a particular subject matter. Few studies have been dedicated to examining the overall impact of emotional leadership on entrepreneurial success. In particular, there are limited studies that have specifically sought to assess the effects and impacts of emotional leadership on the entrepreneurial success of start-ups operating in the hospitality sector. According to Yusof (2014), this is the well-documented positive impact of the hospitality industry to economic growth and improvements in the standards of living. Generally, most studies have focussed on exploring the impact of leadership styles on the entrepreneurial success of start-ups. There has been a general consensus that emotional leadership influences the leadership styles in organisations. For instance, Bass and Avolio (1994) find evidence that emotional leadership has been largely associated with transactional and transformational leadership styles. These leadership styles have particularly been cited as contributing immensely to the achievement of organisational goals and objectives. The limited studies on the impact of emotional leadership on the entrepreneurial success of start-ups and particularly on start-ups that operate in the hospitality sector create a research gap that warrants further interrogation. This research gap creates an opportunity for this study to specifically explore both the direct and indirect effects of emotional leadership on the entrepreneurial success of start-ups with a particular interest in start-ups that operate in the hospitality sector.

\subsection{Objectives of the study}

\subsubsection{General objective}

The general objective of this study is to explore the effects of emotional leadership on the entrepreneurial success of start-ups in the hospitality sector.

\subsubsection{Specific objectives}

The specific objectives of this study are:

i. To examine the direct effects of emotional leadership on the entrepreneurial success of start-ups in the hospitality sector

ii. To examine the indirect effects of emotional leadership on the entrepreneurial success of start-ups in the hospitality sector

\subsection{Research hypotheses}

\section{Hypothesis 1}

Assertiveness of leaders has a significant influence on the performance of followers.

\section{Hypothesis 2}

Empathy of leaders has positive effects on the followers' performance.

\section{Hypothesis 3}

Adaptability of leaders has a substantial effect on the performance of followers.

\subsection{Importance of the study}

Studies should contribute to the body of knowledge. In agreement, Akaranga and Makau (2016) affirm that the main objective of any study or research is to contribute to knowledge. According to these authors, any research or study should expand already existing knowledge. Knowledge is known to make sense when such 
knowledge is shared with other scholars and people. This study will contribute to the body of research on entrepreneurship. Presently, there are limited studies that have been undertaken to examine how emotional leadership affects the entrepreneurial success of start-ups. Generally, the findings of this study will contribute to the body of knowledge on how emotional leadership influences the entrepreneurial success of start-ups.

\subsection{Limitation of the study}

All research studies are limited in some way. Labaree (2009) explains that limitations of studies are those attributes of methodology or research design that have an influence or impact on the findings of a particular study. Generally, limitations of a study constitute those constraints on generalizability, utilisation of findings and applications of study findings to practice. Often, limitations of a particular study arise from the research design, methods of data collection and type of data. Identification and acknowledgement of limitations contribute to enhanced credibility for the research study. The main limitation of this study arises from its intended use of primary data. The choice of use of primary data for this study has been largely shown by its effectiveness in enabling reliable conclusions. In addition, the use of primary data is recommended for its originality and relevance to the research topic. This advantage is critical in facilitating the researchers in meeting the objectives of the study. In fact, Hox (2018) concludes that the originality and relevance of primary data to the research topic explains why this source of data is widely considered to have a high degree of accuracy compared to secondary data. However, the use of primary data may create misleading conclusions, especially, if the responses from the questionnaires are biased. Individual respondent bias has been identified as one of the main limitations of using primary data for analysis. All individuals are known to harbour different biases on any certain subject matter under investigation. Sindhu (2011) identifies other limitations of using primary data for research, including the likelihood of misleading conclusions, being relatively expensive as compared to reliance and dependence on secondary data.

\subsection{Ethical issues and considerations}

The issue of ethics in research has attracted immense attention. Blumberg, Cooper and Schindler (2005) emphasise that researchers must conduct and disseminate their research findings ethically. In particular, these authors insist that researchers should conduct their research in morally accepted ways with strict adherence to ethical principles of research. For the purposes of this study, this researcher will strictly adhere to the following ethical considerations: informed consent, confidentiality and respect for anonymity and respect for respondents' privacy. Armiger (2010) regards the aspect of informed consent as a major ethical consideration in research. Informed consent requires that respondents selected to participate in a particular study knowingly and voluntarily give their consent. Informed consent is largely achieved when all respondents have information on all risks and benefits of participating in the research. In this case, this researcher assures that no individual will be coerced to participate in this study. All respondents will be explained the objectives of the study, and their consent to participate in this study will be sought. In addition, this researcher commits to ensuring that respondents' anonymity is maintained. Akaranga and Makau (2016) consider it critical in addressing the issue of confidentiality in research. This study will ensure that the private information of all respondents is protected as a measure of guaranteeing the confidentiality and anonymity of all respondents. 


\subsection{Organisation of the study}

The rest of this study is organized as follows. Chapter two will present the literature review and focus on previous studies focusing on the impact of emotional leadership on the entrepreneurial success of start-ups with a general bias to the hospitality sector. The literature review will consider varied views and conclusions on the subject matter of this proposal. Chapter three presents various methods and procedures that will be employed for this study. Chapter four of the study will present the main findings. Chapter five will discuss the findings of the study and its implications for future research.

\section{Literature Review}

This chapter presents an overview of the literature that relates to the study. Literature review facilitates researchers in understanding the findings of other related studies. In effect, literature review facilitates identification of research gap basing on the findings of previous related studies. This chapter will demonstrate the significance of the current study. It will review existing related studies on the direct and indirect effects of emotional leadership on entrepreneurial success with particular interest in start-ups.

\subsection{Emotional leadership}

Bambale, Kassim and Musa (2016) explain emotional leadership as essentially in leading followers through both effective identification and management of emotions. According to these scholars, emotional leadership seeks to influence the outcomes of the followers' needs. Stein and Book (2000) find that emotions tend to follow certain logical patterns. According to Goleman, Boyatzis and Mckee (2000), such effective use of emotions is critical for successful leadership. In affirmation, Boyatzis (1982) asserts that this relationship explains why the emotions of organisational leaders tend to contribute to enhanced employee performance. Further, Williams (2001) observes that emotional leadership is critical in shaping the behavioral and cognitive mechanisms of human beings. As such, it has been increasingly recommended that managers and leaders of organizations fully understand the main implications of their emotional leadership on work performance and the success of their organizations.

\subsection{Emotional leadership and entrepreneurial success of start-ups}

There has been increasing interest in the performance and success of start-ups in recent years. Watson, Hogarth-Scott and Wilson (2004) conclude that unlike other firms and enterprises, start-ups and other new small businesses are highly vulnerable to failure. In fact, there is evidence that the majority of start-ups struggle and eventually fail to thrive into prosperous businesses. With such realities, there has been genuine and warranted attention on the determinants of success and failure of start-ups from scholars and other policymakers. Evans and Leighton (2000) observe that despite the evident high failure rate of start-ups, there are numerous motivations for individuals to consider establishing their own small businesses. For instance, high academic qualifications have been known to motivate more individuals to establish their own small businesses rather than seeking employment opportunities. In fact, the available evidence demonstrates that the majority of new business formations are associated with individuals with high academic qualifications and achievements. Individual independence is another driving factor and inducement for the formation of individual small enterprises. Watson, Hogarth-Scott 
and Wilson (2004) also find the high rate of unemployment to be another major motivation for the formation of small businesses.

The entrepreneurial success of start-ups has been explained by numerous factors. These factors have been found to have both direct and indirect impacts on the outcomes of businesses, including start-ups. Interestingly, Gray ( 2001 ) argues that positive business outcomes of start-ups are defined and determined by complex, interrelated factors. This conclusion contradicts the popular argument that there are certain factors that enhance entrepreneurial success of new small businesses. Notwithstanding this argument, Bambale, Kassim and Musa (2016) establish that the relationship between emotional leadership and entrepreneurial success has been largely examined from the impact of emotional leadership on the performance of employees. Hassan, Saeid and Sirous (2010) explain the performance of subordinates/employees as the ability of subordinates/employees to accomplish certain work-related expectations and goals in accordance with previously predetermined standards of work in the workplace. Most studies confirm a positive relationship between emotional leadership and employee performance. Mc Coll and Anderson (2002) establish that emotional leadership has a positive impact on the performance of subordinates. In effect, this study using empirical evidence from 300 respondents working in Australia's pharmaceutical industry affirms leaders' emotions and leadership style positively influence the performance of employees to a significant extent, an aspect that subsequently determines the entrepreneurial success of firms. In particular, this study establishes that optimism and frustrations exhibited by organisational leaders have a direct impact on the performance of subordinates. Leaders who exhibit optimism have a positive impact on the performance of followers. Frustrated organisational leaders have a negative impact on the performance of their employees. Comparatively, Mc Coll and Anderson (2002) find that frustration tends to have a greater and stronger negative impact on subordinates' performance compared to the positive impact of optimism on the performance of followers. These findings further enhance the role of emotions on the performance of followers.

\subsection{Impact of emotional leadership on employee motivation and satisfaction}

\subsubsection{Emotional leadership, employee motivation and entrepreneurial success}

Further, Hassan, Saeid and Sirous (2010) affirm that emotional leadership has a positive impact on the productivity and performance of employees. ${ }^{1}$ According to these authors, leaders' emotions have an impact on employee motivation and satisfaction, factors that have been identified as critical for the entrepreneurial success of start-ups. In agreement, Bambale, Kassim and Musa (2016) maintain that transformational leaders have been found to use their emotions to motivate employees/subordinates. Oyewumi, Ojo and Oludayo (2015) conclude similar findings. According to these scholars, inactions or actions of human beings are largely motivated by emotions. In effect, emotions drive inactions or actions of humans to a significant extent. This relationship has also been used to explain how emotional leadership contributes to enhanced employee performance through its positive influence and impact on the motivation of subordinates. There is evidence that virtually all leadership styles consider the issue of motivation. In particular, it is found that resonant, charismatic and transformational leaders have proved effective in using emotions in a manner that contributes to enhanced motivation for followers and subordinates. Bambale, Kassim and Musa (2016) explain this to be the case since such leaders have the ability to effectively communicate a vision and excite followers to channel their efforts towards the achievement of both strategic and long-term objectives.

The relationship between motivation and entrepreneurial success of firms, including start-ups especially in 
developed countries, has been interrogated to a great extent. Robichaud, McGraw and Roger (2001) and Hornsby and Naffziger (1997) agree that motivation remains one of the critical success factors of entrepreneurs. In fact, these scholars conclude that motivation plays a critical role in business success. Robichaud, McGraw and Roger (2001) explain that the motivation of entrepreneurs can be categorized into four main categories, namely independence/autonomy, extrinsic rewards, family security and intrinsic awards. These categories have been found to influence the level of motivation for entrepreneurs. In effect, independence/autonomy, extrinsic rewards, family security and intrinsic awards determine the extent of business success.

Yimanu (2018) stresses the importance of motivation for entrepreneurial success. According to this scholar, lack of strong motivation has been identified as one of the main reasons for entrepreneurial failure. Entrepreneur motivation is singly important for entrepreneurial success largely due to the fact that motivation enables and facilitates entrepreneurs in meeting the inevitable challenges in the entrepreneurial process. Other available evidence suggests that some of the most successful entrepreneurs globally are self-motivated. This has been closely linked to the fact that self-motivated entrepreneurs tend to be highly productive and efficient. McClelland (1961) considers motivation as an important element in entrepreneurial success due to the fact that such strong motivation encourages the attitude of the high level of risk-taking by entrepreneurs. It is widely known that high -risk investments tend to generate higher returns as compared to low-risk investments. High levels of motivation have also been linked to the enhanced ability of entrepreneurs to identify viable business opportunities (Yimanu 2018). This has been closely associated with the fact that motivation encourages employees to be highly creative.

\subsubsection{Emotional leadership, employee satisfaction and entrepreneurial success}

Similarly, the link between emotional leadership and employee satisfaction resulting in improved employee performance has been established. Locke (1976) defines job satisfaction as the pleasurable emotional state that arises from the appraisal of an individual's job facilitating or contributing to achieving organisational goals and objectives. Omondi (2016) appreciates job satisfaction as a multivariable concept. Various factors have been identified to have a direct effect on the level of job satisfaction. These variables include wages, nature of work, organisational level, working conditions, leadership styles, growth opportunities and working groups. Omondi (2016) identifies other personal factors that determine job satisfaction to include education levels, age, personality and attitudes of individuals. Notably, it is generally argued that younger people, as compared to older people, tend to be more satisfied with their jobs. However, the aspiration levels of individuals tend to increase with age. In instances that the individual's education level does not guarantee expected rewards, it is established that higher educational attainment decreases an individual's levels of job satisfaction. However, Opayemi (2004) contradicts this finding by establishing evidence suggesting that individuals with higher educational levels tend to have a greater commitment to their work as compared the rest with lower academic and educational levels. ${ }^{2}$ In terms of personality, Judge et al. (2000) assert that desirable personality traits of leaders, including high levels of optimism, contribute to the enhanced job satisfaction regardless of workplaces or nature of jobs that individuals are engaged in. Generally, Tett and Meyer (1993) explain that job satisfaction is defined by three main components: affective (emotional) component, cognitive (evaluative) component and behavioural component. From this explanation, it is clearly evident that emotions play a major role in job satisfaction. The emotional component of job satisfaction refers to unpleasant or pleasant feelings that individuals develop towards their jobs over a given period of time. George (2000) emphasizes the critical role of emotions in job satisfaction by affirming that positive emotions have a significant influence on the other components of job satisfaction. As such, there is need for ensuring that employees develop positive emotions towards their work as a way of achieving high 
levels of job satisfaction in the long run. On the contrary, the evaluative component is formed from the individuals' evaluation of their respective job attributes and the general work environment. Lastly, the behavioural component of job satisfaction constitutes the behaviours that occur from the formation of attitude in the workplace. Cammeli ( 2003) finds evidence that all these three components of job satisfaction are critical in employees' formation of job attitude that eventually determines the levels of employee satisfaction.

\subsection{Emotional leadership, emotional intelligence and entrepreneurial success}

Largely, emotional leadership has been closely associated with emotional intelligence.

Ngirande and Harry (2004), using evidence from South Africa, establish that leaders' emotional intelligence contributes to enhanced job satisfaction. In fact, organisational leaders' emotional leadership and emotional intelligence have been known to serve as a competitive edge in both the organisational and personal lives of employees. This study establishes that leaders with high emotional intelligence have a significant positive impact on employee satisfaction.

Harvey ( 2009) agrees that the leaders' emotional intelligence influences job satisfaction levels of subordinates to a great extent. It is established that emotional intelligence facilitates leaders to effectively track the opinions and attitudes of subordinates with the objective of identifying challenges that these subordinates face in the respective discharge of their responsibilities. Through this way, the emotional intelligence of leaders has been found to be effective in allowing leaders to provide better solutions that have related to professional development, training and management in general. In affirmation, Cammeli (2003) argues that emotionally intelligent leaders have the capability and ability of prioritizing important issues that are effective in supporting the achievement of both individual and organisational objectives and aims. Omondi (2016) finds these factors to be singly and collectively crucial in enhancing job satisfaction in the workplace.

Similarly, emotionally intelligent leaders have been found to be highly aware of one's emotions. In addition, these kinds of leaders are increasing aware of what causes one's emotional change and the best way of handling such emotions. In this way, leaders with high levels of emotional intelligence are able to effectively manage subordinates' emotions rather than simply reacting to these emotions. Goleman (2000) finds mere reaction to employee emotions is detrimental to job satisfaction since such have been known to have a high likelihood of damaging relationships. However, better management of subordinates' emotions permits emotionally intelligent leaders to adequately respond to the emotions exhibited by employees/subordinates. According to Omondi (2016), this explains why emotionally intelligent leaders are known for coming up with better and creative decisions that contribute to the achievement of high levels of job satisfaction in their respective workplaces.

On their part, Carmeli and Josman (2006) find the other way in which emotionally intelligent leaders contribute to improvements in job satisfaction to be the fact that such leaders with high emotional intelligence tend to be highly empathic to employees and their work-related challenges. The majority of employee complaints at the workplace have been found to emanate from instances where organisational leaders are not emphatic on issues that confront these employees at the workplace. However, these scholars establish that organisational leaders with high levels of emotional intelligence are able to connect with their subordinates in a more appropriate manner since such leaders can effectively anticipate the way in which employees are reactive to varied situations. Omondi (2016) concludes that such a situation is effective in enabling employees to develop a positive attitude towards work and other colleagues, resulting in high levels of job satisfaction.

The above finding of positive correlation between emotional intelligence of leaders and enhanced employee 
satisfaction has been established by other scholars.

Omondi (2016) establishes that the leaders' emotional intelligence has a greater influence on employee job satisfaction. Start-ups that are characterized and defined by high levels of job satisfaction have greater opportunities and possibilities of entrepreneurial success.

\subsection{Influence of job satisfaction on entrepreneurial success}

Enhanced job satisfaction has been identified as the other factor that determines the entrepreneurial success of start-ups globally. In particular, Fisher (2010) finds entrepreneurial satisfaction to be an important element in the achievement of entrepreneurial success. Walker and Brown (2004) also appreciate the importance and role of personal satisfaction in entrepreneurial success. On their part, Carree and Verheul (2012) consider job satisfaction as the main measure for entrepreneurial success. Specifically, these scholars argue that high job satisfaction at the workplace suggests entrepreneurial success. High levels of job satisfaction have been closely linked to various intrinsic factors and allocation of responsibilities with low-stress levels. With regard to startups, it is found that entrepreneurs derive satisfaction from venture performance. However, other intrinsic factors, including the objectives of establishing the venture, personal attributes and venture characteristics, also define the levels of satisfaction among start-ups.

The above relationship between job satisfaction and entrepreneurial success has also been explained by the reality that satisfaction predicts productivity and performance. Taris and Schreurs (2009) explain that high satisfaction contributes to high levels of productivity and performance, resulting in entrepreneurial success. Several empirical studies have confirmed the role of job satisfaction in the entrepreneurial success of start-ups. For instance, Dej (2011) concludes a positive relationship between subjective entrepreneurial success and job satisfaction. According to this scholar, job satisfaction enhances work engagement. In agreement, Dijkhuizen et al. (2015) affirm that it is enhanced work engagement associated with job satisfaction that contributes substantially to subjective entrepreneurial success. Gorgievski et al. (2014) conclude similar findings that enhanced work engagement arising from job satisfaction are critical for entrepreneurial success considering the role of positive work engagement in subjective business performance and overall business growth of start-ups.

The other way in which job satisfaction has a positive impact on entrepreneurial success is through its role in enhancing stability in the workplace. Headey and Wearing (1989) emphasize the importance of stability for the entrepreneurial success of start-ups. In fact, the instability of these start-ups has been largely linked to the observed high failure rates of start-ups across the world. However, the role of job satisfaction in the stability of start-ups within a short period of time determines the entrepreneurial success of these start-ups both in the short run and long run.

The conclusion of the positive relationship between emotional leadership and the performance of subordinates resulting in greater entrepreneurial success, particularly for start-ups, has been contested by some authors. Notably, Brett (2005), using evidence from South Africa, finds a negative relationship between emotional leadership and the performance of employees. Essentially, this study establishes a weaker relationship between emotional leadership and employee performance. In fact, this study concludes a negative linear relationship between emotional leadership and the performance of subordinates.

Similarly, Bambale, Kassim and Musa (2016) find that emotional leadership is directly and significantly related to performance. This study concludes that the leadership role through the emotion of leaders determines the level of performance of followers. In fact, the effectiveness of leaders is largely dependent on the emotional 
competencies of these leaders. Yusof, Kadir and Mahfar (2014) assert that the ability of leaders to intelligently use their emotions is closely associated with effective leadership. The other ways in which emotional leadership contribute to the enhanced performance of employees are the fact that it increases the quality of decision-making. Rajah, Song and Harvey ( 2011) find this to be the case since emotional leadership facilitates leaders in approaching problems in a more holistic manner.

\subsection{Emotional leadership and leadership styles}

Emotional leadership has been found to have a direct influence on leadership styles adopted by organisational leaders. Peris (2012) affirms that emotional leadership influences leadership styles adopted by organisational leaders. Strong emotional leadership facilitates organisational leaders to consider leadership styles that largely have a positive impact on employee performance. Paladin (2015) considers leadership style to be one of the main factors influencing the entrepreneurial success of firms. According to this scholar, the type of leadership style adopted determines the effectiveness of organisational leaders in tackling emerging challenges and pressures that contemporary firms face. Some of the common pressures and challenges faced by firms, including start-ups in the contemporary business environment, include challenges emanating from change and improvements on enterprise performance. As such, effective leadership is considered to be critical in ensuring that firms meet future and current business.

The relationship between leadership styles and subordinate performance, particularly for start-ups and small businesses, has been interrogated to some extent. Iqbal, Anwar and Haider ( 2015) identify the different leadership styles to include democratic, autocratic and participative styles. In a democratic leadership style, decisions are made within teams. In effect, all members are accorded opportunities to contribute to the decisions made by the leaders. In participative leadership styles, all team members identify essential goals and collectively contribute to developing strategies and procedures necessary for the attainment of these goals. In effect, leaders that practice participative leadership style act as facilitators rather than simply issuing instructions and orders to subordinates. For the autocratic leadership style, the leaders of teams issue instructions and orders to subordinates and develop an expectation for obedience to these orders and instructions without arguments. The members of the team are isolated in decision making. Accordingly, Heneman and Gresham (1999) find that the decision-making process is centralized in an autocratic leadership style. The leaders do not solicit and accept initiatives and suggestions from the members. One of the primary benefits of the autocratic leadership style is that it facilitates faster decision making. However, this leadership style has been closely associated with employee exploitation and distortion.

The influence of leadership styles on employees' performance and entrepreneurial success has also been examined to a great extent. Umer, Adna and Hamid (2012) explore the impact of leadership styles on the performance of employees in Pakistan. Using evidence from various Pakistani schools, this study concludes that leadership styles determine subordinate performance. In particular, Iqbal, Anwar and Haider ( 2015) establish that participation leadership style has a long-term positive impact on the performance of subordinates working for start-ups and small businesses. In addition, these authors find that autocratic and democratic leadership styles also positively impact employee performance. However, they find that the autocratic leadership style tends to have an immediate and short-term positive impact on employee performance as compared to the rest of the leadership styles. Democratic leadership style has a significant positive impact on subordinate performance in the middle term. This finding affirms Umer, Adna and Hamid's (2012) conclusion that leadership styles have a positive 
impact on employee performance. However, Heneman and Gresham (1999) contest this conclusion affirming a positive relationship between autocratic leadership style and employee/subordinate performance. According to these scholars, autocratic leadership style has a greater likelihood of contributing to the de-motivation of employees resulting in poor work performance. In support, Ittner (2002) concludes that autocratic leadership style restricts employee initiative and activities. This has been associated with the fact that the autocratic leadership style restricts socialization and communication in the workplace.

Transformational and transactional leadership has been specifically identified to have a direct impact on the performance of followers. Bass and Avolio (1994) explain that the transformational leadership style includes the creation of enthusiasm between followers or employees engaged in a particular organisation. In addition, transformational leadership is known for encouraging new perspectives among employees, a development that has been found to contribute significantly towards ensuring that the main objectives of the organisation are known by all employees. This has been found to enhance the performance of firms since it promotes motivation among team members and increases the capability of employees in discharging their responsibilities and duties.

Paladin (2015) concludes that the effectiveness of the transformational leadership style in achieving entrepreneurial success is closely linked to the fact that the majority of current challenges facing business enterprises, including start-ups, are transformational. In particular, most of these challenges are largely driven by diverse client needs and the external environment. Transformational leaders are able to offer better solutions to these challenges since these leaders are known for their flexibility of mindset. Mc Coll and Anderson (2002) acknowledge the existing relationship between emotional leadership and leadership styles and its subsequent impact on the performance of subordinates. According to these authors, emotional leadership has been found to encourage transformational leadership. Transformational leaders tend to be highly optimistic, an aspect that has been found to have a positive impact on the performance of followers. Mc Coll and Anderson (2002) clarify that although the overall effect and impact of transformational leaders on the performance of subordinates are significant, this relationship is indirect. This conclusion contradicts the common argument that transformational leadership has a direct impact on the performance of followers and therefore has a direct positive impact on the entrepreneurial success of start-ups.

Several leadership studies have examined the impact of transformational leadership style in the workplace. Tee and Tse (2009) find that transformational leaders are largely considered more efficient by employees. In affirmation, Hur et al. (2011) find evidence of greater efficiency of transformational leadership by establishing that transformational leaders tend to achieve greater team achievements. Similarly, transformational leaders have been associated with enhanced cooperation with their followers. In addition, transformational leaders demonstrate better utilisation of skills and have been known to be largely effective in inspiring, influencing and motivating their followers. These benefits explain the present preference for the adoption of transformational leadership styles in the workplace as such has been closely associated with both individual and collective organisational success.

Contrary to the transformational leadership style, transactional leadership includes disciplining and rewarding employees basing on the individual output of these employees (Yusof, Kadir and Mahfar 2014). Leaders that adopt a transactional leadership style lay greater emphasis on completion of tasks, standards of jobs and conformity of workers. In effect, transactional leaders manage their followers through disciplining and offering rewards as a strategy of attaining the greatest level of efficiency. 


\subsection{Summary and research gap}

From the literature review, it is clear that very few studies have sought to explore the direct and indirect effects of emotional leadership on the entrepreneurial success of start-ups. The majority of existing studies have largely examined the influence of emotional leadership on the performance of employees. Most of these studies consider the performance of employees/followers, is critical for entrepreneurial success. It is worth noting that most of the available studies conclude a positive impact of emotional leadership on employee performance. In particular, it is established that emotional leadership determines the level of entrepreneurial success of firms through its impact on employee satisfaction and motivation. Notably, employee motivation is considered as a crucial component of the entrepreneurial success of firms (McClelland 1961). This conclusion has been justified by the fact that motivation encourages high tendencies of risk-taking, a development that increases possibilities and chances of entrepreneurial success. Similarly, employee satisfaction is particularly considered as the other factor that determines the entrepreneurial success of firms to a great extent. Effective emotional leadership by organisational leaders facilitates employees in developing positive emotions towards their work (George 2000). The other way in which emotional leadership has been linked to entrepreneurial success is through emotional intelligence. A review of the literature reveals that emotionally intelligent leaders are able to prioritise important tasks that are necessary for the achievement of entrepreneurial success. In particular, emotionally intelligent leaders tend to be fully aware of their employees' emotions, and as such, these leaders can make better-informed decisions that contribute to improved productivity and eventual attainment of desirable levels of entrepreneurial success. Similarly, emotionally intelligent leaders are associated with transformational leadership styles. Such transformational leadership style is established to play a critical role in the entrepreneurial success of firms since this type of leadership style is highly flexible and responsive to emerging needs of the customers and changing market conditions. However, there are limited studies that have specifically sought to establish the effects of emotional leadership on the entrepreneurial success of start-ups. This is the existing voluminous literature on small businesses and entrepreneurship. This current study seeks to fill this gap by exploring both direct and indirect effects of emotional leadership on the entrepreneurial success of start-ups in the hospitality sector. The findings of this study will expand and enhance existing knowledge on emotional leadership and entrepreneurial success through evidence from start-ups that operate in the hospitality sector.

\section{Research Methodology}

This chapter presents a discussion on the research methodology of the study. Primarily, this chapter will present, discuss and justify the methodologies adopted for the study. In addition, it will also discuss why the chosen methodologies will be useful with regard to the achievement of the aims and objectives of the study. Generally, Žukauskas (2018) acknowledges that the manner in which research is conducted can be conceived in terms of the research philosophy that has been adopted, the research strategy that has been used and the research instruments that have been used in data collection in the overall pursuit of the research objectives. This discussion in this chapter will include research philosophy, research design, research strategy, target population, sampling techniques, research instruments, sample size, data collection, data analysis and validity and reliability. 


\subsection{Research philosophy}

Research philosophy is considered as a critical element of research methodology. Saunders, Lewis and Thornhill (2015) explain research philosophy to be a system of assumptions and beliefs on the development of knowledge. From this definition, it is clear that research philosophy is essentially the belief about the manner in which data that relates to a particular phenomenon should be gathered, analyzed and utilized. Research philosophy is precisely the reason why individuals engage in research: to develop knowledge in a certain field. Most studies have contributed to knowledge development by offering solutions and answers to a specific research problem. The assumptions of research include epistemological assumptions, axiological assumptions and ontological assumptions. According to Crotty (1998), these assumptions eventually determine how the researchers generate understanding on the research questions, interpretation of findings and the choice of methods to be used in the conduct of research. Credible research philosophy is achieved with consistent and well-thought assumptions.

With the above explanation, research philosophy can be taken to mean the guides that inform the choice of research design, data collection methods, and data analysis. Saunders, Lewis and Thornhill (2009) explain that research philosophy enables the researcher to decide which of the approaches to be adopted. In addition, these scholars find that research philosophies justify the choice of research approaches adopted by the researchers. This explains the argument that the choice of research philosophy determines the choice of research strategy, methodological choice and techniques of data collection. It is acknowledged that the research philosophy adopted for a particular study must be derived from the research questions. This implies that the research questions determine the type of research philosophy adopted by a particular study. It must also be appreciated that important assumptions of the study are contained in the research philosophy.

The common research philosophies are the positivist approach ${ }^{3}$ and the interpretivist approach ${ }^{4}$. The positivist approach is largely related to the philosophical stances of natural scientists. Generally, this approach includes working from social reality that can be observed. According to Saunders, Lewis and Thornhill (2009), this is intended to generate law-like generalizations. These law-like generalizations are universal, definite in nature and applicable for everybody. Further, Levin (1988) observes that positivists consider the reality of being highly stable. From this consideration, positivists assert that reality can be both observed and described objectively. This implies that a particular phenomenon can be observed and described without interfering with it. However, the positivist approach contends that this is largely possible in the situations that the phenomenon under study can be isolated and that the observations on the phenomenon can be repeated. In addition, the positivism approach encourages the manipulation of reality using single independent variables. This is intended to ensure that the researcher is able to identify all regularities and establish any relationships that exist between variables under study. One of the advantages of the positivist approach is that it has been known to generate accurate and unambiguous results that contribute to the body of knowledge. However, some scholars, including Hirschheim (1985), have raised concerns on the suitability of the positivist approach, particularly for social sciences. This concern has supported the increasing preference for alternative research philosophies that are more pluralistic in nature for social sciences. Others find adoption and use of positivist approach are responsible for the observed inconsistencies in results. In fact, this aspect has been used to highlight the inappropriateness of positivism as an approach to research philosophy.

Saunders, Lewis and Thornhill (2009) observe that the interpretivist approach emerged from the criticism of 
positivism. This criticism was largely based on the above imminent shortcomings of the positivism approach. The interpretivist approach maintains that meaning is relative. In particular, the interpretivist approach offers criticism to the positivist approach's attempts to discover universal laws applicable to all.

This research philosophy finds that there is no single truth, and as such, the interpretivist approach argues that there is a need for generating understanding of participants within a given context. The interpretivist approach lays great emphasis on the reality and fact that human beings differ from the physical phenomena. According to the positivist approach, this difference between physical phenomena and human beings largely arises from the fact that human beings, unlike physical phenomena, have the ability of creating meanings. The interpretivists are interested in studying these meanings. As such, Crotty (1998) observes that this difference informs the interpretivists' argument that the physical phenomena and human beings cannot be studied in a similar way. This approach acknowledges that individuals of diverse cultural backgrounds, at different times and under different circumstances, tend to create different meanings. Equally, these individuals experience and create diverse social realities.

Generally, the interpretivists argue that the full understanding of reality can only be achieved through subjective intervention and interpretation. The study of phenomena in their natural environment forms the core of the interpretivist approach. In addition, the positivists maintain that the researchers are unable to avoid interfering with phenomena in their natural environment while undertaking their studies. In summary, the interpretivist approach concludes the existence of numerous interpretations of reality due to the issue of subjectivity and relativity. According to interpretivists, subsequent variations in the relative interpretation of a phenomenon are critical in contributing to the body of knowledge. Interpretivism seeks to create rich and new interpretations and understandings of social worlds and contexts.

This current study adopts a positivist approach. The choice for the positivist approach has been largely informed by the fact that the current study seeks to test identified hypotheses. The positivist approach has been largely recommended as effective and appropriate for studies seeking to test hypotheses. In fact, Saunders, Lewis and Thornhill (2009) reveal that most positivist researchers have preferred using existing theory in developing their respective hypotheses. These hypotheses would be tested and confirmed, partially or wholly, or completely refuted. In addition, the choice for the positivist approach has been informed by the fact that it guarantees unambiguous and accurate knowledge.

\subsection{Research design}

Research design is essential in research since it does the research to become more efficient. In fact, a good research design ensures that researchers access maximum information with fewer resources. In effect, research design makes research cost-effective. This study adopts a descriptive survey to ascertain the direct and indirect effects of emotional leadership on the entrepreneurial success of start-ups in the hospitality sector. Anastas (1999) explains that descriptive research designs enable researchers to access information on the state of a particular phenomenon in context. The choice of descriptive research design for this study has been largely influenced by the fact that descriptive research designs have been known to contribute to the development and expansion of knowledge.

\subsection{Research strategy}

Saunders et al. (2009) explain research strategy, in context of research methodology, to be the general plan 
that the researcher intends to use in finding solutions and answers to the proposed research questions. There are various existing research strategies that researchers can consider for their investigation. Wright (2010) identifies the main types of research strategies: surveys, experiments, ethnography, case studies, action research, grounded theory, and archival research. The above types of research strategies can be categorized into two main classifications: qualitative research strategies and quantitative research strategies. Bridgmon (2013) reveals that qualitative research strategies include exploratory studies, case studies, action research and grounded theory. On the contrary, quantitative research strategies include laboratory experiments and survey research. In the current study, survey research is undertaken. In particular, the views of the respondents are collected through the administration of questionnaires. In survey research, the researchers use the sample of the whole population and subsequently generalize the findings from the sample to the whole population. In particular, the survey collected relevant data that will allow the researcher to determine the direct and indirect effects of emotional leadership on the entrepreneurial success of start-ups in the hospitality sector. Its relative ease largely informed the choice of the survey strategy of implementation. In addition, the consideration of surveys for the current study has been informed by the fact that such surveys allow researchers to undertake an extensive study on numerous variables at a time. This is practically impossible with other research strategies, including field experiments (Wright, 2010). However, the main limitation of surveys relates to the issue of researchers' bias. In particular, it is documented that researchers may have a bias in identifying respondents to participate in the study. In addition, researchers' bias may be reported in the choice of survey design.

\subsection{Target population}

Cox (2013) explains target population as the entire set of units in which the study seeks to collect data. The collected data is to be used to make appropriate inferences. Generally, the target population provides the needed foundation for the researchers to enhance the reliability and validity of a study under consideration. Essentially, the target population provides the objects that will facilitate the study in understanding a particular problem. Population means all members that meet the specified criterion to be considered as participants in a particular study. The target population for this study are employees ( subordinates) working for start-ups in the hospitality sector. Essentially, this study seeks to understand the impact of emotional leadership on the performance of employees/subordinates working for start-ups in the hospitality sector. This study will use the performance of employees/subordinates working for start-ups in the hospitality sector as a proxy for the overall success of the start-ups in the hospitality sector.

\subsection{Sampling technique}

Sampling is critical for research. It is generally appreciated that the target population of a study is often large. In view of this, it becomes impractical to conduct a study on the entire target population. In fact, it is established that sampling is critical towards the achievement of the broader objectives of the research. Sampling allows researchers to infer information of the larger population based on the information that is collected from a subset of such population (Molenberghs 2018). Sampling allows researchers to achieve a significant reduction in cost and workload and facilitates access to high-quality information that will help in the achievement of the overall objectives of the study. Inadequate sampling has been known to jeopardize the integrity of the overall study. In fact, failure to consider appropriate sampling techniques compromises the entire research process.

Probability sampling (random sampling) and non-probability sampling have been identified as the two main 
sampling techniques that researchers can consider (Cox 2013). In probability sampling, the researchers specify the probability of a respondent being considered and selected in the sample. Probability sampling is recommended for researchers interested in the generalization of the findings that have been derived from the selected sample to the target population. In this case, probability sampling becomes more precise and useful. However, probability sampling is very expensive as compared to non-probability sampling. In non-probability sampling, there is no estimation of the probability of a participant being selected in the sample. This study will adopt a simple random sampling technique. In a simple random sampling technique, the respondents of the study are chosen randomly by chance. In effect, each of the elements in the target population has an equal chance of being considered and selected as a sample. The choice of a simple random sampling technique for this study has been largely informed by the fact that this sampling technique has been found to be effective in reducing selection bias in research. In addition, simple random sampling has been found to be desirable in generalizing the findings of the sample to the entire target population (Bridgmon 2013). In fact, proper selection of samples allows researchers to make representative inferences for the entire target population.

\subsection{Sample size}

Sample size refers to the group of objects that have been selected for participation in a particular study. Essentially, a sample refers to the selected elements from the target population. ${ }^{5}$ Various strategies for determining the right sample size of a study have been proposed. The sample size for this study is 100 participants. The number of objects selected for this study is informed by the availability of time and finances to conduct the study. The researcher of the current study considers 100 respondents as the representative sample size of individuals working in the hospitality sector (target population) and that the findings and inferences from this sample size will provide appropriate generalizations.

\subsection{Research instruments}

Research instruments are crucial in data collection. There are several research instruments that can be considered depending on the nature of the study. Largely, this study will use research questionnaires. Questionnaires are considered the main research instruments in the conduct of surveys. This research instrument provides standardized questions that have been designed in a way that collects relevant information from the respondents on specific research topics. Essentially, questionnaires are administered with the primary purpose of collecting information and data from the selected respondents.

\subsection{Data collection}

The choice of data collection techniques is imperative as this determines whether the overall objectives of the study will be met. Different data collection methods are recommended for different types of data. It is recommended that the choice of data collection methods and techniques be determined by the research problem and the research objectives (Athukorala 2011). The data for this research will be collected using questionnaires. The target population for this study is employees/workers engaged in start-ups in the hospitality sector. The researcher will collect data from 100 respondents.

\subsection{Data analysis}

The primary objective of data analysis is to reduce and synthesise data collected through the preferred 
research instruments. Data analysis is intended to facilitate the researcher in making sense of the data collected. In addition, data analysis enables researchers to make appropriate inferences on a target population basing on the data collected from the sample population. Quantitative data analysis and qualitative data analysis are identified as the main approaches to data analysis. Thomas et al. (2015) reveal that quantitative data analysis employs various statistical data analysis techniques while qualitative data analysis uses non-statistical data analysis methods and techniques. The current study adopts quantitative data analysis. In particular, data collected in this study from the questionnaires will be analysed using SPSS. The data collected from the questionnaires will be examined and checked for both comprehensibility and completeness. The researcher also made a summary, coded and tabulated the data. The descriptive statistics from the data was used in establishing existing relationships between the various variables of the study. In particular, the descriptive statistics, including percentages, mean and standard deviation was considered in the analysis of data. In addition, inferential statistics was also considered in determining how various aspects of emotional leadership influenced the entrepreneurial success of start-ups in the hospitality sector.

\subsection{Statistical tests}

The choice of statistical tests is largely dependent on the nature of the study. Basically, statistical tests facilitate researchers in making quantitative decisions on a given sample from the target population. These statistical tests also help in the testing of the hypotheses of the study. The Chi-Square test will be used as a statistical test for this study. Essentially, the Chi-Square test determines the statistical significance of the variables used in the study (Mindrila 2018). Chi-Square test tests relationships between categorical variables. The null hypothesis of the Chi-Square test is the non-existence of the relationship between categorical variables. The choice of Chi-Square test for this study has been largely informed by the sample size ( 100 respondents). It is documented that the Chi-Square test tends to be highly sensitive to sample size. This statistical test is not suited for large samples exceeding 500 respondents. If used with such large samples, a small difference will appear to be statistically significant.

\subsection{Reliability analysis}

High reliability of data is considered as an important component for any research. Mohajan (2017) finds reliability analysis to be a fundamental and important feature in evaluating any measurement instrument used for research purposes. Essentially, reliability analysis describes the reliability of data towards the achievement of the overall objectives of the study. In effect, reliability analysis ascertains whether particular research will produce consistent and stable findings. Reliability analysis determines whether a particular scale can consistently reflect the same conclusions of the construct under measurement. According to Mohajan (2017), reliability analysis concerns the faith in which one has in the data that is collected from the use of the particular instrument. Cronbach Alpha Reliability analysis will be considered for this study. Cronbach Alpha Reliability analysis has been commonly considered as a reliability analysis measure. Cronbach Alpha Reliability analysis splits data into two and subsequently computing the correlation coefficient for each half set of data. The value of Cronbach Alpha Reliability analysis is essentially the average of these two values. ( To be continued in the next issue)

Note:

1 This relationship has been largely explained by the fact that leaders' emotions generate productive behaviour among employees/subordinates. 
2 In fact, this aspect has elicited immense debate on whether an employee's level of education has a direct positive impact on their levels of job satisfaction.

3 The positivist approach has a rich and long historical tradition. This explains why the positivist approach has become highly embedded in society to the extent that any study conclusions and knowledge claims that are not based on positivist thought has been largely dismissed and discounted as invalid and unscientific.

4 The interpretivist approach emerged in the early and mid-20th century across Europe. This approach of research philosophy has been attributed to German, English and French thinkers.

5 When all members of the target population are considered and selected as respondents in a study, such is referred to as census.

\section{References}

Agarwal, R. (2017). Assertive leadership and employee engagement and its impact on retention. International Journal in Multidisciplinary and Academic Research, 1, 1-20.

Akaranga, S. and Makau, B. (2016). Ethical considerations and their applications to research: A case of the University of Nairobi. Journal of Educational Policy and Entrepreneurial Research, 12, 1-9.

Bambale, A., Kassim, S. and Musa, L. (2016). Effect of emotional leadership on employee performance among the staff of Tertiary Institutions in Gombe. Journal of Resources Development and Management, 19, 23-31.

Bass, B. M. (1985) . Leadership and performance beyond expectations. New York: Free Press.

Bass, B. M. and Avolio, B. J. (1994). Improving organizational effectiveness through transformational leadership. Thousand Oaks, CA: Sage.

Blumberg, B, Cooper D.R and Schindler P.S. (2005). Business research methods. Berkshire: Mc Graw Hill.

Brett, A. (2005). Relationship between employee performance, leadership and emotional intelligence in a South African parastatal organisation. Dissertation, Rhodes University.

Crotty, M. (1998). The foundations of social research. London: Sage.

Dej, D. (2011). Exploring entrepreneur success from a work psychology perspective: The development and first validation of a new instrument. Dissertation, TU Dresden.

Dijkhuizen, J., Gorgievski, M., Van Veldhoven, M. and Schalk, R. (2015). Feeling successful as an entrepreneur: A job demands -resources approach. International Entrepreneurship and Management Journal, 2, 555-573.

Gentry, W., Weber, T. and Sadri, G. (2007). Empathy in the Workplace. Center for Creative Leadership. See https://cclinnovation. org/wp-content/uploads/2020/03/empathyintheworkplace.pdf.

George, J. M. (2000) . Emotions and leadership: The role of emotional intelligence. Human Relations, 53, 1027-1055.

Gorgievski, M. J., Moriano, J. A. and Bakker, A. B. (2014). Relating work engagement and workaholism to entrepreneurial performance. Journal of Managerial Psychology, 29, 106-121.

Hassan, J., Saeid, J. and Sirous, K. (2010). Impact of emotional intelligence on performance of employees. Postmodern Openings, 4 , $63-74$.

Headey, B. and Wearing, A. (1989). Personality, life events, and subjective well-being: Toward a dynamic equilibrium model. Journal of Personality and Social Psychology, 57, 731-739.

Heneman, R.L. and Gresham, M.T. (1999). The effects of changes in the nature of work on compensation. Ohio: Ohio State University, USA.

Hornsby, J. and Naffziger, D. (1997). An examination of owners' goals in sustaining entrepreneurship. Journal of Small Business Management, 35(1), 24-33.

Hunter, J.E., Schmidt, F.L. andJudiesch, M.K. (1990). Individual indifferences in output variability as a function of job complexity. Journal of Applied Psychology, 75, 28-42.

Hur, Y., van den Berg, P. T. and Wilderom, C. P. M. (2011). Transformational leadership as a mediator between emotional intelligence and team outcomes. The Leadership Quarterly, 4, 591-603. 
Iqbal, I., Anwar, A. and Haider, H. (2015) . Research article open access effect of leadership style on employee performance. Arabian Journal of Business and Management Review, 5, 146-154.

Ittner, C., \& Larcker, D. (2002). Determinants of performance measure choices in worker incentive plans. Journal of Labor Economics (Special Issue), 20, $58-90$.

Locke, E.A. (1976) . 'The Nature and Causes of Job Satisfaction', In M.P Dunnette (Ed.). Handbook of industrial and organizational psychology. Chicago: Rand McNally.

Mc Coll, J. and Anderson, R. (2002). Impact of leadership style and emotions on subordinate performance. The Leadership Quarterly, $5,545-559$.

McClelland, D. (1961). The achieving society. New York: The Free Press.

Natalie, L., Jackson, J. and Sharon, L. (2010). The effects of emotional intelligence, age, work experience, and academic performance. Research in Higher Education Journal, 9, 1-18.

Ngirande, H. and Harry, T. (2004). The relationship between leader emotional intelligence and employee job satisfaction. Mediterranean Journal of Social Sciences, 5, 25-52.

Oladipo et al. (2013). Relationship between employee performance, leadership styles and emotional intelligence in an organization. IOSR Journal of Humanities and Social Science, 2, 53-57.

Omondi, G. (2016). Influence of manager's emotional intelligence on employee job satisfaction at the kenya post office savings bank. Dissertation, Nairobi: University of Nairobi.

Rajah, R., Song, Z., and Arvey, R. D. (2011). Emotionality and leadership: Taking stock of the past decade of research. The Leadership Quarterly, 6, 1107-1119.

Robichaud, Y., McGraw, E. and Roger, A. (2001). Toward the development of a measuring instrument for entrepreneurial motivation. Journal of Developmental Entrepreneurship, 1, 189-202.

Saunders, M. N., Lewis, N. K. and Thornhill, P. (2009). Understanding research philosophies and approaches. London: Pearson.

Stein, S. J. and Book, H. E. (2000). The EQ edge: emotional intelligence and your success. Canada: Multi-Health Systems.

Taris, T. W. andSchreurs, P. J. G. (2009) . Well-being and organizational performance: An organization-level test of the happyproductive worker hypothesis. Work \& Stress, 2, 120-136.

Williams, S. (2001). Emotion and social theory. London: Sage.

Yimanu, N. (2018). Entrepreneurship and entrepreneurial motivation. Dissertation, Centria University of Applied Sciences.

Yusof, H., Kadir, H. and Mahfar, M. (2014). The role of emotions in leadership. Asian Social Science, 10, 41-50.

( Editor: Nelson) 